\title{
BERYLLIUM-7 SPECIFIC ACTIVITY IN SURFACE AIR AND ITS CORRELATION WITH METEOROLOGICAL VARIABLES, SOLAR ZENITH ANGLE, AND NUMBER OF SUNSPOTS
}

\author{
Jelena Ajtić1,2*, Vladimir Djurdjevic ${ }^{3}$, Darko Sarvan', \\ Erika Brattich ${ }^{4}$, Miguel A. Hernández-Ceballos5
}

\author{
${ }^{1}$ Faculty of Veterinary Medicine, University of Belgrade, Belgrade, Serbia \\ ${ }^{2}$ Institute for Research and Advancement in Complex Systems, Belgrade, Serbia \\ 3Institute of Meteorology, Faculty of Physics, University of Belgrade, Belgrade, Serbia \\ 4Environmental Chemistry and Radioactivity Laboratory, Department of Chemistry "G. Ciamician", Alma Mater \\ Studiorum University of Bologna, Bologna, Italy \\ 5European Commission, Joint Research Centre, Institute for Transuranium Elements, Nuclear 7 Security Unit, Ispra, \\ Italy
}

\begin{abstract}
This analysis presents linear correlations of beryllium-7 specific activity in surface air with several variables measured in Helsinki, Finland, over 1987-2011. Measurements of beryllium-7 are linearly correlated with the following 10 variables: tropopause height; mean, minimum and maximum temperature; precipitation; atmospheric pressure; potential vorticity at $300 \mathrm{hPa}$ and $200 \mathrm{hPa}$; solar zenith angle; and the number of sunspots. A time lag is also introduced into the calculations of Pearson's linear correlation coefficients, i.e. the beryllium-7 specific activity measured on a day is correlated with a value of a given variable measured on some preceding day. In particular, the time lag is allowed to vary between $o$ and 7 days for tropopause height, meteorological parameters and potential vorticity, and between $o$ and 31 days for solar zenith angle and number of sunspots. In this way, we obtain sets of correlation coefficients for each pair of the analysed variables, in which we look for the maximum correlation coefficient as well as for the time lag on which this value is reached. In addition to investigating all of the available measurements, the time series are further split into seasonal subsets. Weak to moderate maximum correlation coefficients, ranging between 0.29 and 0.44 , are found for the beryllium-7 specific activity with the tropopause height, temperatures and atmospheric pressure. These correlations are reached with a time lag of $0-2$ days. Seasonal correlation coefficients show that the strongest linear relationships are obtained in summer. Similarly, a moderate correlation (o.48) with the solar zenith angle is reached with a time lag of o days, but the seasonal correlation coefficients in this case show a weaker relationship during different seasons. On the other hand, our analysis suggests that the correlations of beryllium-7 with precipitation, potential vorticity and the number of sunspots are not statistically significant.
\end{abstract}

Key words: Beryllium-7, surface air, linear correlations, meteorological variables, solar activity

DOI: $10.21175 /$ RadProc.2016.19

\section{INTRODUCTION}

Beryllium-7 (half-life 53.22 days) is a naturally occurring radionuclide that is produced in the upper troposphere and lower stratosphere [1]. After production, $7 \mathrm{Be}$ attaches to fine aerosols [2]-[4], and its ensuing behaviour in the atmosphere is governed by air mass transport and removal mechanisms [5], [6]. Therefore, ${ }^{7 B e}$ reaching the surface could be an indicator of a number of atmospheric processes, and indeed, the ${ }^{7}$ Be specific activity in surface air has been studied in relation to meteorological variables [7]-[11], solar activity [5], [9], [12], [13], large-scale atmospheric transport [6], [14]-[16], and tropopause height [11], [17].

In Europe, the $7 \mathrm{Be}$ measurements have been conducted with a relatively sparse temporal and spatial resolution [18], [19]. A notable exception is a $7 \mathrm{Be}$ database compiled in Helsinki, Finland. This database contains measurements of the 7 Be specific activity in surface air between 1987 and 2011, with a total number of measurements larger than 4000. This dataset is stored by the online Radioactivity Environmental Monitoring (REM) Database. More information on the REM Database can be found on its website: http://rem.jrc.ec.europa.eu/.

In this paper, the $7 \mathrm{Be}$ specific activity measured in Helsinki was linearly correlated with the following ten variables: tropopause height; mean, minimum and maximum temperature; precipitation; atmospheric pressure; potential vorticity at $300 \mathrm{hPa}$ and $200 \mathrm{hPa}$; solar zenith angle; and number of sunspots. As already mentioned, the 7 Be specific activity in surface air has been previously studied in relation to some of the chosen variables, but the investigated sets of variables

*jelena.ajtic@vet.bg.ac.rs 
encompassed shorter time periods and contained fewer data points. In that respect, the linear correlations studied in this paper represent novel results. Further, the two additional variables, potential vorticity and solar zenith angle, that were included in the analysis, could offer a broader insight into the overall mechanisms that influence the $7 \mathrm{Be}$ surface concentration.

\section{MATERIALS AND METHODS}

\section{1. ${ }^{7}$ Be database}

Measurements of the $7 \mathrm{Be}$ specific activity in surface air in Helsinki $\left(60.21{ }^{\circ} \mathrm{N}, 25.06{ }^{\circ} \mathrm{E}\right)$, Finland, performed between 1987 and 2011, are stored in the Radioactivity Environmental Monitoring Database (REMdb) supported by the REM group of the Institute of Transuranium Elements of the DG JRC. The REMdb gives a wider collection of different radionuclides' measurements in a number of environmental sample types, wherein the $7 \mathrm{Be}$ specific activities in surface air in 34 locations across Europe are also included. More details on the REMdb and 7 Be specific activity measurements are given in [20], [21]. The 7Be database stored in the REMdb is public until 2006, and the access to the data corresponding to the 2007-2011 period can be granted only after explicit request.

In the Helsinki $7 \mathrm{Be}$ dataset, two subsets can be distinguished: until 1999, the sampling was performed once a week, while in the subsequent years, the sampling frequency increased to every day or once in two days. The Helsinki database now comprises more than 4000 measurements.

\subsection{Meteorological variables}

Tropopause height was calculated according to the procedure given in [17]. The input data for the calculations were taken from the NCEP/NCAR reanalysis [22]. The calculations consisted of two steps. First, an extrapolation of isobaric heights above and below the tropopause to the tropopause pressure was performed using the hydrostatic approximation. Second, the average value of the two extrapolated values was taken as the height of the tropopause. Daily values of tropopause height were thus obtained for each day over the investigated period 1987-2011.

Meteorological variables, consisting of the mean, minimum and maximum temperature, atmospheric pressure, and precipitation, were obtained from the European Climate Assessment \& Dataset (ECA\&D) [23]. These series consisted of daily data.

Potential vorticity (PV) is a product of absolute vorticity on a given level and static stability. High PV values can indicate a lowering of the tropopause and an intrusion of stratospheric air into the troposphere. Cross-sections of the atmosphere show that PV values of around 2 PVU (1 PVU $=10^{-6} \mathrm{~m}^{2} \mathrm{~s}^{-1} \mathrm{~K} \mathrm{~kg}^{-1}$ ) are typical for the extratropical tropopause [24]. Daily values of potential vorticity at two pressure levels, $300 \mathrm{hPa}$ and $200 \mathrm{hPa}$, were used in our study.

The solar zenith angle is defined as the angle between the zenith and the sun position. Path length that the solar beam travels through the atmosphere to the surface is approximately inversely proportional to the cosine of the zenith angle, and direct solar irradiance on a horizontal surface is proportional to the cosine of the angle [25].

The daily sunspot data were obtained from the SIDC-team (World Data Center for the Sunspot Index, Royal Observatory of Belgium, Monthly Report on the International Sunspot Number, online catalogue of the sunspot index: http://www.sidc.be/sunspotdata/1987-2011).

\subsection{Methodology}

Linear relation between the 7 Be specific activity and other variables was investigated using Pearson's linear correlation coefficients. Statistical significance of the coefficients was also calculated (Student $t$-test, significance level $p=0.05$ ), and only statistically significant coefficients are presented.

First, the whole set of the available ${ }^{7} \mathrm{Be}$ measurements were used to calculate the correlation coefficients with other variables. To investigate the seasonal relations, the time series were further split into the autumn (September-November), winter (December-February), spring (March-May), and summer (June-August) subsets.

A time lag was also introduced into the calculations of Pearson's linear correlation coefficients-the $7 \mathrm{Be}$ specific activity measured on a given day was correlated with a value of a matching variable measured on some preceding day. In particular, the time lag was allowed to vary between o and 7 days for the tropopause height, meteorological parameters and potential vorticity, and between 0 and 31 days for the solar zenith angle and number of sunspots. In this way, sets of correlation coefficients for each pair of analysed variables were obtained. Within these sets, we looked for the maximum correlation coefficient as well as for the time lag on which this value was reached. The number of days corresponding to the maximum correlation coefficient indicates the time needed for changes in the atmospheric conditions to be registered in the ${ }^{7 B e}$ concentration measured in surface air.

\section{RESUlts AND Discussion}

Fig. 1 shows the monthly means (over 1987-2011) of the $7 \mathrm{Be}$ specific activity in surface air, tropopause height, maximum daily temperature, precipitation, atmospheric pressure, potential vorticity at $200 \mathrm{hPa}$, solar zenith angle and number of sunspots. Tab. 1 lists the calculated Pearson's linear correlation coefficients.

Apart from the 7 Be specific activity, the tropopause height, maximum temperature, $\mathrm{PV}$ at $200 \mathrm{hPa}$, and solar zenith angle also showed notable annual cycles with maxima during the warmer half of the year (Fig. 1). However, none of these maxima coincided with the 7Be maximum, which occurred early during the warm season (in May). It was followed by the PV at $200 \mathrm{hPa}$ and solar zenith angle maxima in June, while the maximum daily temperature and tropopause height reached their maxima in July and September, respectively.

The calculated linear correlation coefficient (Tab. 1) showed that the similarities in the annual cycles are not necessarily the evidence of a linear relationship 
between the variables. For example, for the total set of measurements (Tab. 1), weak, but statistically significant, correlations for the $7 \mathrm{Be}$ specific activity with the tropopause height, temperatures and solar zenith angle were obtained. Statistically significant linear correlation was also obtained for atmospheric pressure which did not exhibit a similar annual cycle (Fig. 1). On the other hand, despite the similarities in the annual cycles of the ${ }^{7 B e}$ surface concentration and $\mathrm{PV}$ at $200 \mathrm{hPa}$, the correlation coefficients were not statistically significant (Tab. 1).

The seasonal correlation coefficients for the tropopause height showed the strongest linear relation in summer. During transition seasons (autumn and spring) the relationship was weaker, and least pronounced in winter (Tab. 1). The time lag was mostly one day, indicating that changes in the tropopause height were quickly reflected in the ${ }^{7 B e}$ concentration in surface air.

Our correlation coefficients implying a certain degree of linear relationship between the 7 Be surface concentration and tropopause height are in general agreement with previously reported results for other locations [11], [17]. However, the number of days at which the maximum correlation is reached (Tab. 1) is shorter than three days found for Thessaloniki, Greece [17]. This disagreement could result from the true variability in atmospheric conditions between Helsinki and Thessaloniki, or could be a spurious result arising from differences in investigated periods (the Thessaloniki time series consisted of weekly measurements performed during 2009).

Meteorological variables, the temperatures and atmospheric pressure, exhibited a similar degree of influence on ${ }^{7} \mathrm{Be}$ as the tropopause height (Tab. 1). The correlation coefficients were weak to moderate, with the strongest linear correlation in summer. In winter, however, the correlation was not statistically significant. The changes in temperatures and atmospheric pressure were mirrored by changes in $7 \mathrm{Be}$ within the same day and two days later, respectively. On the other hand, the correlation coefficients implied no linear correlation with precipitation, which is considered a major removal process of $7 \mathrm{Be}$ from the atmosphere [7], [9], [26].

These finding are also in general agreement with the available data. For example, a linear correlation coefficient of $\sim 0.50$ for the $7 \mathrm{Be}$ specific activity in surface air and temperature, was reported for Málaga, Spain [3] and Monaco [9]. Correlation coefficients for other meteorological variables, though, were not as consistent - while in Málaga, the $7 \mathrm{Be}$ surface concentration was anticorrelated with precipitation

and relative humidity [3], the Monaco records showed no statistically significant linear correlation [9].

For the total set of measurements, a moderate correlation of 0.48 was found for the $7 \mathrm{Be}$ surface concentration and solar zenith angle and it was reached with a time lag of zero days (Tab. 1). The seasonal correlation coefficients in this case showed a weaker relationship during different seasons, in contrast to other seasonal coefficients that implied the strongest relationships in summer.

The solar zenith angle, with its smooth and pronounced annual cycle (Tab. 1), was included in the analysis as a possible proxy for a physical property which was omitted from the analysis. In this sense, the inclusion of the solar zenith angle was made in an effort to allow for another variable not previously analysed. The moderate linear correlation coefficient of 0.48 found for the solar zenith angle (Tab. 1) might imply an existence of a contributing factor with the following properties: 1) it exhibits a marked annual cycle, and 2) its influence on the $7 \mathrm{Be}$ specific activity in surface air is less pronounced during seasons than during the whole year.

Figure 1. Monthly means of (top to bottom): 7Be specific activity, tropopause height (TH), maximum daily temperature (TX), precipitation (RR), atmospheric pressure (PP), potential vorticity (PV) at $200 \mathrm{hPa}$, solar zenith angle (SZA), and number of sunspots (SS).

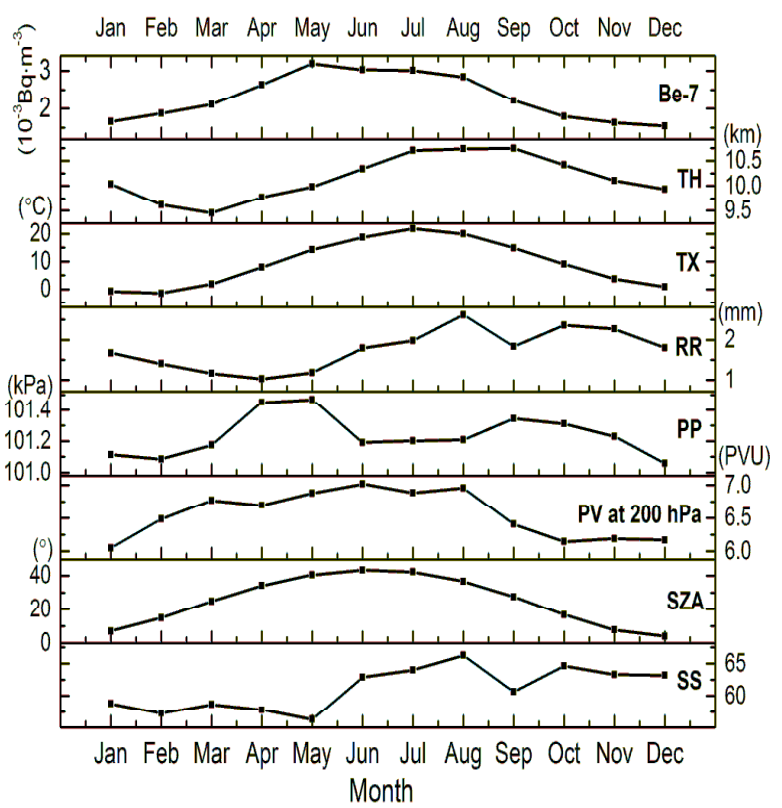


Table 1. Correlation coefficients of the 7Be specific activity in surface air: maximum Pearson's linear correlation coefficients (m.c.c.) and the number of days (n.d.) on which they were reached. Correlation coefficients not statistically significant are indicated by cells shaded in grey.

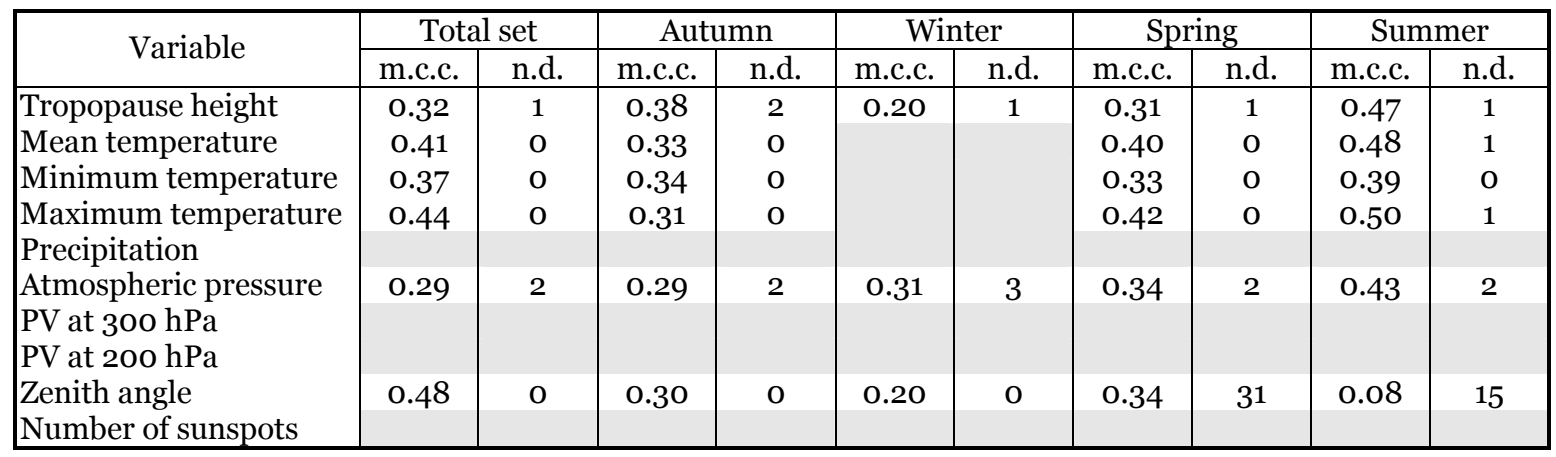

Our analysis further suggested that the correlations of the $7 \mathrm{Be}$ specific activity with the number of sunspots and potential vorticity were not statistically significant. Solar activity has been previously studied in relation to $7 \mathrm{Be}$, and the inverse relationship between the number of sunspots and 7Be surface concentration has been found. For example, the aforementioned Monaco records [9] and data for Palermo, Italy [13], showed strong anticorrelation between these variables. However, the ${ }^{7 B e}$ surface concentrations in Finland seem to show a stronger response to atmospheric conditions than to solar activity [27], which could result in an insignificant correlation with the number of sunspots as shown in our analysis.

Potential vorticity was included in our calculations for the following reasons. High PV values are often used as an indicator of stratospheric air intrusion to the lower atmospheric levels [28]. Therefore, for the upper troposphere, regions with high values of PV can be seen as a potential source of $7 \mathrm{Be}$ [29]. Previous studies have investigated a relation between PV and the ${ }^{7}$ Be specific activity in surface air [30]-[32], but not a linear correlation between them. Our result, showing no significant linear correlation between these two variables, could arise from the fact that after the intrusion, air masses were not necessarily subjected to a direct descent. They could reach the surface via an indirect transport involving advection. Hence, this finding might suggest that horizontal and vertical transport exhibit similarly important influence on the 7Be specific activity in the lower tropospheric levels.

\section{CONCLUSION}

Linear relationship between the $7 \mathrm{Be}$ surface concentration and eight meteorological variables, as well as the solar zenith angle and number of sunspots, was analysed. A weak to moderate correlation was found for the tropopause height, temperatures and atmospheric pressure. The strongest linear relationships were obtained in summer. These results were in agreement with previously reported data. Our analysis further showed that changes in the tropopause height, temperatures and atmospheric pressure were quickly (within two days) reflected in the $7 \mathrm{Be}$ concentration changes. The moderate correlation obtained for the solar zenith angle might indicate an existence of a variable linearly correlated with the $7 \mathrm{Be}$ surface concentration, but which was not identified in our study.

On the other hand, our analysis suggested that the correlations with precipitation, potential vorticity and number of sunspots were not statistically significant. The absence of a statistically significant correlation with potential vorticity most likely implies that after reaching the upper levels of the troposphere, the stratospheric air is not transported directly to the surface, thereby the location of the intrusion of $7 \mathrm{Be}-$ rich air is not positioned directly above Helsinki. Further, the lack of correlation with the number of sunspots could support a hypothesis that transport in the troposphere plays a significant role on the $7 \mathrm{Be}$ distribution at the surface.

Acknowledgement: The paper is a part of the research done within the project "Climate changes and their influence on the environment: impacts, adaptation and mitigation" (No. 43007) financed by the Ministry of Education, Science and Technological Development of the Republic of Serbia (2011-2016). The authors would like to thank the REM group for provision of the beryllium-7 specific activity measurements from the REM database (REMdb at the Institute of Transuranium Elements, REM group, $D J$ JRC Ispra site, European Commission).

\section{REFERENCES}

1. D. Lal and B. Peters, "Cosmic Ray Produced Radioactivity on the Earth," in Kosmische Strahlung II / Cosmic Rays II, K. Sitte, Ed., Berlin, Germany: Springer, 1967, pp. 551-612

2. D.M. Koch, D.J. Jacob and W.C. Graustein, "Vertical Transport of Tropospheric Aerosols as Indicated by ${ }^{7} \mathrm{Be}$ and ${ }^{210} \mathrm{~Pb}$ in a Chemical Tracer Model," J. Geophys. Res., vol. 101, no. D13, pp. 18651-18666, Aug. 1996

3. C. Dueñas, M.C. Fernández, J. Carretero, E. Liger and S. Cañete, "Long-Term Variation of the Concentrations of Long-Lived Rn Descendants and Cosmogenic $7 \mathrm{Be}$ and Determination of the MRT of Aerosols," Atmos. Environ., vol. 38, no. 9, pp. 1291-1301, March 2004

4. U. Heikkilä, J. Beer and V. Alfimov, "Beryllium-10 and Beryllium-7 in Precipitation in Dübendorf (440 M) and at Jungfraujoch (3580 M), Switzerland (1998-2005)," $J$. Geophys. Res., vol. 113, no. D11, June 2008

5. E. Gerasopoulos, C.S. Zerefos, C. Papastefanou, P. Zanis and K. O'Brien, "Low-Frequency Variability of 
Beryllium-7 Surface Concentrations over the Eastern Mediterranean," Atmos. Environ., vol. 37, no. 13, pp. 1745-1756, Apr. 2003

6. P. Cristofanelli et al., "A 6-Year Analysis of Stratospheric Intrusions and their Influence on Ozone at Mt. Cimone (2165 m above Sea Level)," J. Geophys. Res., vol. 111, no. D3, Feb. 2006

7. C. Papastefanou and A. Ioannidou, "Depositional Fluxes and other Physical Characteristics of Atmospheric Beryllium-7 in the Temperate Zones $\left(40^{\circ} \mathrm{N}\right)$ with a Dry (Precipitation-Free) Climate," Atmos. Environ. A, vol. 25, no. 10, pp. 2335-2343, 1991

8. D. Todorovic, D. Popovic and G. Djuric, "Concentration Measurements of $7 \mathrm{Be}$ and ${ }^{137 \mathrm{Cs}}$ in Ground Level Air in the Belgrade City Area," Environ. Int., vol. 25, no. 1, pp. 59-66, Jan. 1999

9. M.K. Pham, M. Betti, H. Nies and P.P. Povinec, "Temporal Changes of $7 \mathrm{Be},{ }^{137 \mathrm{Cs}}$ and $210 \mathrm{~Pb}$ Activity Concentrations in Surface Air at Monaco and their Correlation with Meteorological Parameters," $J$. Environ. Radioact., vol. 102, no. 11, pp. 1045-1054, Nov. 2011

10. J.V. Ajtić, D.J. Todorović, J.D. Nikolić and V.S Djurdjević, "A Multi-Year Study of Radioactivity in Surface Air and its Relation to Climate Variables in Belgrade, Serbia", Nucl. Technol. Radiat., vol. 28, no. 4, pp. 381-388, Dec. 2013

11. L. Tositti, E. Brattich, G. Cinelli and D. Baldacci, "12 Years of $7 \mathrm{Be}$ and ${ }^{210} \mathrm{~Pb}$ in Mt. Cimone, and their Correlation with Meteorological Parameters," Atmos. Environ., vol. 87, pp. 108-122, Apr. 2014

12. D.M. Koch and M.E. Mann, "Spatial and Temporal Variability of 7Be Surface Concentrations," Tellus B, vol. 48, pp. 387-396, 1996

13. F. Cannizzaro, G. Greco, M. Raneli, M.C. Spitale and E. Tomarchio, "Concentration Measurements of $7 \mathrm{Be}$ at Ground Level Air at Palermo, Italy - Comparison with Solar Activity over a Period of 21 Years," J. Environ. Radioact., vol. 72, no. 3, pp. 259-271, 2004

14. J. Hedfors, A. Aldahan, A. Kulan, G. Possnert, K.-G. Karlsson and I. Vintersved, "Clouds and 7Be: Perusing Connections between Cosmic Rays and Climate," $J$. Geophys. Res., vol. 111, no. D2, Jan. 2006

15. A.-P. Leppänen et al., "Cosmogenic 7 Be in Air: A Complex Mixture of Production and Transport", J. Atmos. Sol. Terr. Phys., vol. 72, no. 13, pp. 1036-1043, Aug. 2010

16. A.-P. Leppänen, I.G. Usoskin, G.A. Kovaltsov and J. Paatero, "Cosmogenic ${ }^{7 \mathrm{Be}}$ and ${ }^{22} \mathrm{Na}$ in Finland: Production, Observed Periodicities and the Connection to Climatic Phenomena", J. Atmos. Sol. Terr. Phys., vol. 74, pp. 164-18o, Jan. 2012

17. A. Ioannidou, A. Vasileiadis and D. Melas, "Time Lag between the Tropopause Height And 7Be Activity Concentrations on Surface Air," J. Environ. Radioact., vol. 129, pp. 80-85, Mar. 2014

18. A. Kulan, A. Aldahan, G. Possnert and I. Vintersved, "Distribution of $7 \mathrm{Be}$ in Surface Air in Europe," Atmos. Environ., vol. 40, no. 21, pp. 3855-3868, July 2006

19. B.R.R. Persson and E. Holm, " $7 \mathrm{Be},{ }^{210} \mathrm{~Pb}$, and ${ }^{210} \mathrm{Po}$ in the Surface Air from the Arctic to Antarctica," J. Environ. Radiact., vol. 138, pp. 364-374, Dec. 2014

20. M.A. Hernández-Ceballos et al., "A Climatology of 7Be in Surface Air in European Union," J. Environ. Radioact., vol. 141, pp. 62-70, Mar. 2015

21. M.A. Hernández-Ceballos, G. Cinelli, T. Tollefsen, and M. Marín-Ferrer, "Identification of Airborne Radioactive Spatial Patterns in Europe - Feasibility Study Using Beryllium-7," J. Environ. Radioact., vol. 155-156, pp. 5562, May 2016

22. E. Kalnay et al., "The NCEP/NCAR 40-Year Reanalysis Project," Bull. Am. Meteorol. Soc., vol. 77, no. 3, pp. 437471, Mar. 1996
23. A.M.G. Klein Tank et al., "Daily Dataset of 20th-Century Surface Air Temperature and Precipitation Series for the European Climate Assessment," Int. J. Climatol., vol. 22, no. 12, pp. 1441-1453, Oct. 2002

24. M.E. McIntyre, "Dynamical Meteorology | Potential Vorticity," in Encyclopedia of Atmospheric Sciences, G.R. North, J. Pyle and F. Zhang, Eds., Cambridge (MA), USA: Academic Press, 2014, pp 375-383

25. R.E. Bird and R.L. Hulstrom, Simplified Clear Sky Model for Direct and Diffuse Insolation on Horizontal Surfaces, Golden (CO), USA: SERI, 1981.

26. A. Ioannidou and C. Papastefanou, "Precipitation

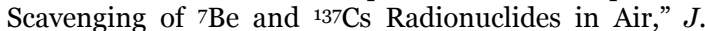
Environ. Radioact., vol. 85, no. 1, pp. 121-136, 2006

27. A.-P. Leppänen and J. Paatero, "7Be in Finland during the 1999-2001 Solar Maximum and 2007-2009 Solar Minimum", J. Atmos. Sol. Terr. Phys., vol. 97, pp. 1-10, May 2013

28. J.R. Holton, P.H. Haynes, E.M. McIntyre, A.R. Douglass, R.B. Rood and L. Pfister, "Stratosphere-Troposphere Exchange," Rev. Geophys., vol. 33, no. 4, pp. 403-439, Nov. 1995

29. E.F. Danielsen, "Stratospheric-Tropospheric Exchange Based on Radioactivity, Ozone and Potential Vorticity," J. Atmos. Sci., vol. 25, pp. 502-518, May 1968

30. P. Cristofanelli et al., "A 6-Year Analysis of Stratospheric Intrusions and their Influence on Ozone at Mt. Cimone (2165 m above Sea Level)," J. Geophys. Res., vol. 111, no. D3, Feb. 2006

31. E. Gerasopoulos, P. Zanis, C. Papastefanou, C. S. Zerefos, A. Ioannidou and H. Wernli, "A Complex Case Study of down to the Surface Intrusions of Persistent Stratospheric Air over the Eastern Mediterranean," Atmos. Environ., vol. 40, no. 22, pp. 4113-4125, July 2006

32. E. Cuevas et al., "Assessment of Atmospheric Processes Driving Ozone Variations in the Subtropical North Atlantic free Troposphere," Atmos. Chem. Phys., vol. 13, pp. 1973-1998, Feb. 2013 